\title{
Screening, detecting and enhancing the yield of previously undiagnosed hepatitis $B$ and $C$ in patients with acute medical admissions to hospital: A pilot project undertaken at the Vancouver General Hospital
}

\author{
Jordanna E Kapeluto MD¹, Matthew Kadatz MD , Andrew Wormsbecker MD¹, \\ Kiran Sidhu MD ${ }^{1}$, Eric M Yoshida MD FRCPC ${ }^{2}$
}

\begin{abstract}
JE Kapeluto, M Kadatz, A Wormsbecker, K Sidhu, EM Yoshida. Screening, detecting and enhancing the yield of previously undiagnosed hepatitis $\mathrm{B}$ and $\mathrm{C}$ in patients with acute medical admissions to hospital: A pilot project undertaken at the Vancouver General Hospital. Can J Gastroenterol Hepatol 2014;28(6):315-318.
\end{abstract}

BACKGROUND: Hepatitis B virus (HBV) and hepatitis C virus (HCV) represent an increasing health burden and morbidity in Canada. Viral hepatitis, specifically HCV, has high prevalence among persons born between 1945 and 1965, with 45\% to 85\% of infected adults asymptomatic and unaware of their infection. Screening has been shown to be cost effective in the detection and treatment of viral hepatitis.

OBJECTIVE: To quantify incidence and identify undocumented HBV and HCV infection in hospitalized patients at a single centre with secondary analysis of risk factors as part of a quality improvement initiative. METHODS: A one-time antibody test was conducted in patients admitted to the acute medicine and gastroenterology services.

RESULTS: Over a 12-week period, hospital screening for HBV and HCV was performed in $37.3 \%$ of 995 admitted patients. There was identification of 15 previously undiagnosed cases of HCV (4\%) and 36 undocumented cases of occult (ie, antihepatitis B core antigen seropositive) or active (ie, hepatitis B surface antigen seropositive) HBV (9.7\%). Among patients with positive screens, $60 \%$ of seropositive HCV patients had no identifiable risk factors.

CONCLUSIONS: The prevalence of HBV and HCV infection among hospitalized patients in Vancouver was higher than that of the general population. Risk factors for contraction are often not identified. These results can be used as part of an ongoing discussion regarding a 'seek and treat' approach to the detection and treatment of chronic bloodborne viral illnesses.

Key Words: Cirrhosis; Hepatitis; Hospitalized patients; Quality improvement; Screen
Le dépistage, la détection et l'amélioration du taux de diagnostic chez des patients atteints d'hépatite B ou $\mathrm{C}$ non diagnostiquée hospitalisés en soins aigus : un projet pilote du Vancouver General Hospital

\begin{abstract}
HISTORIQUE : Le virus de l'hépatite B (VHB) et le virus de l'hépatite $\mathrm{C}(\mathrm{VHC})$ représentent un fardeau croissant pour la santé et la morbidité au Canada. L'hépatite virale, notamment le VHC, a une prévalence élevée chez les personnes nées entre 1945 et 1965, de $45 \%$ à $85 \%$ des adultes infectés étant asymptomatiques et ne se sachant pas infectés. Le dépistage s'est révélé rentable pour déceler et traiter l'hépatite virale.

OBJECTIF : Quantifier l'incidence du VHB et du VHC, en dépister l'infection chez des patients hospitalisés dans un centre unique dont la maladie n'était pas inscrite au dossier et procéder à une analyse secondaire des facteurs de risque dans le cadre d'une initiative d'amélioration de la qualité.

MÉTHODOLOGIE : Test d'anticorps unique chez les patients admis aux services de médecine aiguë et de gastroentérologie.

RÉSULTATS : Pendant une période de 12 semaines, 37,3\% des 995 patients admis se sont soumis au test de dépistage du VHB et du VHC en milieu hospitalier. Les médecins ont ainsi dépisté 15 cas de VHC (4\%) auparavant non diagnostiqués et 36 cas non inscrits au dossier de VHB occulte (séropositifs à l'antigène capsidique de l'hépatite B) ou actif (séropositifs à l'antigène de surface de l'hépatite B) $(9,7 \%)$. Chez les patients ainsi dépistés, $60 \%$ de patients séropositifs au VHC ne présentaient pas de facteur de risque identifiable.

CONCLUSIONS : La prévalence d'infections par le VHB et le VHC chez les patients hospitalisés de Vancouver était plus élevée que celle de la population générale. Souvent, les facteurs de risque de contamination ne sont pas connus. Ces résultats peuvent être utilisés dans le cadre d'une discussion continue sur une démarche de dépistage et de traitement des maladies hématogènes chroniques d'origine virale.
\end{abstract}

Chronic infection with hepatitis B virus (HBV) or hepatitis C virus (HCV) may result in end-stage cirrhosis and hepatocellular carcinoma, and can result in multiple acute hospitalizations over the disease course. Data from Ontario collected between 2005 and 2007 indicate that HCV has the highest burden of disease of any infectious disease, with HBV ranked fifth, above that of HIV (1). In British Columbia, the incidence of HCV infection varies (54.9 cases per 100,000 ), with a higher rate in Vancouver (71 cases per 100,000). Rates of HBV cases provincially $(29.5$ per 100,000$)$ and 83.5 cases per 100,000 in Vancouver, compared with HIV, which occurs at 7.6 and 6.8 cases per 100,000 , respectively (2).
HCV was recently shown to have a higher prevalence in persons born between 1945 and 1965, often without identifiable risk factors. Of infected persons, $45 \%$ to $85 \%$ are unaware of their diagnosis and, thus, do not receive targeted therapy or education $(3,4)$. No standardized recommendations for screening of viral hepatitis exist in Canada (5). Current hepatitis screening recommendations for HCV in the United States vary. The Centers for Disease Control and Prevention (CDC, Georgia, USA) recommends testing individuals of all ages with identifiable risk factors including exposures to intravenous drug use, hemodialysis, blood transfusion before 1992 or elevated alanine aminotransferase levels; and to administer one-time testing to all

${ }^{1}$ Department of Medicine; ${ }^{2}$ Division of Gastroenterology, University of British Columbia, Vancouver, British Columbia

Correspondence: Dr Matthew Kadatz, 10th Floor, 2775 Laurel Street, Vancouver, British Columbia V5Z 1M9. Telephone 604-875-4111 ext 61561, fax 604-875-5447, e-mail mkadatz@gmail.com

Received for publication August 31, 2013. Accepted April 28, 2014 
persons born between 1945 and 1965 without ascertainment of risk (4). The US Preventive Services Task Force recently modified their position, which is now consistent with the $\operatorname{CDC}(6,7)$.

Clinical trials combining protease inhibitors with pegylated interferon have shown a sustained response in viral suppression at varying rates (between $46 \%$ and $81 \%$ for HCV genotypes 1 and 2 or 3) depending on the genotype $(5,8,9)$. With early identification and appropriate treatment, antiviral therapy has shown to reduce disease burden, with an estimated $70 \%$ reduction in hepatocellular carcinoma and $50 \%$ reduction in all-cause mortality $(10,11)$. Antibody screening has been shown to be cost effective, with a reduction in disease-related morbidity and mortality if they lead to improved referral and treatment $(12,13)$.

In 2012, a health authority-funded HIV screening program of patients admitted to Vancouver area hospitals was initiated but did not include HBV nor HCV $(14,15)$. In the present article, we report a hospital-based, internal medicine residency quality assurance project that serologically screened for HBV and HCV in patients admitted to an acute medicine/gastroenterology service at the Vancouver General Hospital, Vancouver, British Columbia. The infection risk factors and disease incidence were examined as well as the magnitude of the increased screening of chronic HBV/HCV compared with baseline, as a result of the program.

\section{METHODS}

\section{Study oversight}

The present study was conducted as part of a hepatitis screening initiative for a quality improvement project through the University of British Columbia in Vancouver, British Columbia. The authors performed data collection and analysis. Approval for the present project was obtained through the University of British Columbia Clinical Research Ethics Board. All patients screened provided verbal consent for testing through their primary care giver in hospital.

\section{Study population}

Patients newly admitted to the acute medicine teaching unit and gastroenterology services between July 25 and November 15, 2012 at Vancouver General Hospital were included in the present study. Admissions came directly from emergency department referrals. Patients transferred from the intensive care unit to the medical service, or from other hospitals, were not included. Data from patients admitted to hospital multiple times during the study period were only included from the initial admission.

\section{Study design}

The data collected for the present project were part of a quality improvement initiative using three consecutive four-week 'Plan, Do, Study, Act' (PDSA) cycles to increase rates of hepatitis screening. Cycles involved education sessions, posters and reminders placed on patient charts. Data from the four-week period immediately before the implementation of the screening program were collected to serve as a baseline comparator.

Eligible patients were screened by the in-hospital medical resident physician for hepatitis B surface antigen (HBsAg), anti-hepatitis B surface antibody (HBsAb), anti-hepatitis B core antibody ( $\mathrm{HBcAb}$ ) and anti-HCV antibody (anti-HCV Ab). In-hospital medical residents were instructed to obtain verbal consent from patients before testing and document such in the chart. Refusal to provide consent was random without selection bias. Patients who did not agree to participate were not tested as part of this screening initiative. The result of the test was disclosed to the patient during the hospital admission. Also, a copy of the results was sent to the patient's community general practitioner if results were not available by time of discharge. The patients were provided with medical advice to follow up with their general practitioner. It was beyond the scope of the present study to examine the outcomes in terms of how many patients followed-up with their community general practitioner, underwent treatment, or were referred to a hepatologist or infectious diseases specialist. Patients with positive $\mathrm{HCV} \mathrm{Ab}$ testing in hospital were offered confirmatory testing.

Screening numbers, including total number of tests ordered, composition of tests and patient demographics, including age, sex and risk factors, were obtained from electronic patient records in the four weeks before the study time period and at each PDSA cycle. Risk factors were identified according to CDC guidelines and included history of intravenous or intranasal drug use, history of work in the sex-trade industry, treatment with blood products or organ transplant before 1992, chronic hemodialysis, exposure to tattoo instruments, needle stick injury in a health care setting and persistently abnormal alanine aminotransferase levels. Immigration from an endemic area and household or maternal exposure could not be ascertained from electronic patient charts and were not included (14). There were limitations in what information could be obtained using this method given that it required the primary care physician to obtain all relevant history and document this in the chart. All patients with a positive anti-HCV Ab, $\mathrm{HBcAb}$ without an $\mathrm{HBs} \mathrm{Ab}$, and $\mathrm{HBs} \mathrm{Ag}$ were considered to have positive screens. $\mathrm{HBcAb}$ was included given the implications for potential need of immunosuppression, and the possibility of reactivation in the future. Patients with $\mathrm{HBs} A g$-positive screens were considered to have active or carrier state hepatitis infections. Patients with positive HBV DNA on follow-up testing were considered to be active. For all patients with positive screens, previous hospital admission data were reviewed. This was considered to be a newly positive screen if previous testing had not been conducted and with no documentation of a previous HCV or HBV diagnosis; or if patients' previous screening had been negative. Patients awaiting liver transplant assessment were excluded, as were patients transferred from other hospitals and not admitted through the emergency room. Although it was not always possible to exclude the possibility of a hepatitis serology being ordered for another reason beyond a screen, patients with hepatitis serologies ordered for diagnosis of elevated liver enzyme levels or liver mass were excluded from the analysis.

\section{Study outcomes}

The primary end point of the study was to increase rates of screening for HBV and HCV among unselected medical/gastroenterology patients admitted to the Vancouver General Hospital. Secondary end points included identification of undocumented HBV and HCV, and examination of identifiable risk factors among hospitalized patients.

\section{Statistical analysis}

Statistical analyses were performed using the Fisher's exact test, with $\mathrm{P}=0.05$ considered to be indicative of statistical significance. Statistical analysis was performed using Excel (Microsoft Corporation, USA) as well as Minitab (Minitab, USA).

\section{RESULTS}

During the 16 weeks of data collection, a total of 1257 patients were admitted to the acute medicine and gastroenterology services at the Vancouver General Hospital (not all of whom were eligible for the present study [ie, transferred from another hospital for liver disease]). The gastroenterology patients enrolled were admitted for luminal/ pancreatic disorders or for therapeutic endoscopy). Of these, 102 were admitted to gastroenterology while the remainder were admitted to the acute medicine service. Four weeks of baseline data collection demonstrated screening in 67 of $233(28.8 \%)$ patients admitted to acute medicine service and 17 of $29(58.6 \%)$ patients admitted to gastroenterology. A total of $32(12.2 \%)$ nonselective, with regard to previous screening before presentation to hospital, hepatitis screens in the baseline population were positive. Eight $(25 \%)$ of the patients with positive screens had no previous documentation of positive hepatitis serology and had no identifiable risk factors for HBV or HCV on electronic chart review.

During three sequential PDSA cycles over a 12-week period, an additional 995 patients were admitted to the acute medicine and 
TABLE 1 Admission and screening data according to service during
baseline data collection and study period at Vancouver
General Hospital, Vancouver, British Columbia

\begin{tabular}{lccc}
\hline & & \multicolumn{2}{c}{ Service } \\
\cline { 3 - 4 } & Total & Medicine & Gastroenterology \\
\hline Admissions & 1257 & 1156 & 101 \\
Baseline* $^{*}$ & 262 & 233 & 29 \\
Study period $^{\dagger}$ & 995 & 923 & 72 \\
Patients screened & 455 & 410 & 45 \\
Baseline & 84 & 67 & 17 \\
Study period & 371 & 343 & 28 \\
\hline
\end{tabular}

Data presented as $n$. *Weeks 1 to 4 ; ' Weeks 5 to 16

gastroenterology services (Table 1). The rate of screening among these patients increased to $37.3 \%(\mathrm{P}=0.129)$ combined (ie, 371 screened patients). Screening for hepatitis among patients admitted to the internal medicine service increased significantly by $8.4 \%$ to $37.2 \%$ $(\mathrm{P}=0.017)$. Among patients admitted to the gastroenterology service screening decreased by $20.3 \%$ to $38.4 \%$, although this decline was not statistically significant $(\mathrm{P}=0.079)$.

Of the patients screened during the 12 weeks of interventions, 15 of $371(4 \%)$ patients were found to have a positive anti-HCV Ab with no history of a positive antibody test (Table 2). There were no identifiable risk factors on electronic chart review in nine of the $15(60 \%)$ anti-HCV positive patients. Eight of the $15 \mathrm{HCV}$-positive patients were between 45 and 65 years of age and five of those eight patients had no identifiable risk factors for viral hepatitis. There were 36 of $371(9.7 \%)$ patients with previously undocumented positive HBV screen, 31 with evidence of previous or occult HBV infection (ie, anti$\mathrm{HBc}$ seropositive), and five patients with active or carrier state HBV infection (ie, HBsAg seropositive). All of the patients with evidence of previous/occult or current HBV infection had no identifiable risk factors on electronic chart review. Overall, 113 patients had identifiable risk factors for viral hepatitis on chart review. Of these, 30 (26.5\%) had no documentation of previous or in-hospital screen.

Combining the three sequential PDSA cycles in which active protocol screening was undertaken with the four weeks of baseline data collection, where protocol screening did not occur (ie, screening was at the discretion of the attending medical/gastroenterological services), a total of 455 patients were tested for viral hepatitis serological markers. Eighty-three (13.1\%) patients had a positive serological test.

\section{DISCUSSION}

The incidence of chronic viral hepatitis in British Columbia and Vancouver exceeded that of HIV; however, detection in asymptomatic patients remains low with no existing standardized screening recommendations $(1,5)$. In addition, the health care burden associated with the relatively young age of $\mathrm{HCV}$-infected patients with undetected disease will increase in the next few decades and lead to increases in health care spending, demonstrating the need for early detection (16).

The present study shows a high incidence of undetected HBV- and HCV-positive serology among hospitalized patients in Vancouver, with $13.7 \%$ of patients screened during our initiative demonstrating a positive antibody test. This result is similar to positive screens from the baseline data (12.2\%) before protocol screening was implemented. The relatively higher serological incidence during baseline before implementation of protocol screening likely reflects a pre-initiative selection bias in which patients were tested if there were known symptoms (jaundice, ascites), risk factors (active intravenous drug use) or admission for liver transplant assessment, hepatocellular carcinoma management, etc. The higher rate of overall screening in the intervention phase diluted the rate of positive screens because the denominator was larger; however, there was an overall higher absolute number of positive screens in the intervention phase (51 versus 32 ), $70.6 \%$ of which were asymptomatic or without identifiable risk factors.
TABLE 2

Incidence and demographics of patients with positive screening tests at Vancouver General Hospital (Vancouver, British Columbia) during the study period

\begin{tabular}{lccc}
\hline & Not previously & \multicolumn{2}{c}{ Risk factors } \\
\cline { 3 - 4 } documented & Not identified & Identified \\
\hline Positive anti-HCV & 15 & 9 & 6 \\
Age $<45$ years & 5 & 3 & 2 \\
Age 45 to 65 years & 8 & 3 & 5 \\
Age $>$ 65 years & 2 & 0 & 2 \\
Positive HBV screen & 36 & 27 & 9 \\
Carrier & 1 & 1 & 0 \\
Active & 4 & 1 & 3 \\
Previous infection & 31 & 25 & 6 \\
\hline
\end{tabular}

Active Positive hepatitis B virus (HBV) surface antigen; Anti-HCV Anti-hepatitis $C$ virus antibody; Carrier Positive HBV core antigen; Previous infection Positive HBV core antigen and HBV surface antigen

With only a $30 \%$ rate of screening in the implementation phase of protocol screening, the 51 positive screens suggests that a subset of the hospitalized patient population may have undetected viral hepatitis that is not otherwise being recognized. It is not possible to report whether the limited rate of screening was due to patient refusal of testing or a matter of the primary care physician forgetting to enroll patients and not ordering the test. The latter is understandable in a very busy hospital emergency room where clinical concerns are the priority. It is reasonable to assume that either would have been a random chance effect and would have equally affected those who would have had a positive test result and those who would have had a negative test result. We could not absolutely exclude selection bias for screening based on the limitations of chart review; however, with respect to risk factor-based screening, it was our experience that many patients did not have a dedicated history taken for viral exposure on routine admission to hospital (data not shown). Similarly, community physicians vary in their practices of asking about major viral hepatitis risk factors, while patients may also omit information that would place them at risk for transmission (17-19). As such, a significant proportion of patients at risk for HBV and HCV are not being identified based on risk factors or birth cohort. Although only five of the 36 patients with a positive HBV serological test were active carriers (ie, HBsAg positive), it is important to note that having previous infection, as indicated by an anti-HBc seropositive test, may not necessarily be benign. This group of anti-HBc seropositive patients can still experience reactivation of $\mathrm{HBV}$, which has been reported to be fatal under the influence of potent immunosuppression during oncological chemotherapy or solid organ transplantation (20,21). Moreover, occult HBV as indicated by a seropositive anti-HBc has been suggested to be an etiological factor in the development of otherwise idiopathic primary hepatocellular carcinoma (22). Our finding of a high rate of serological positivity for HBV (9.7\%) most likely reflects the demographics of the population of metropolitan Vancouver (especially Vancouver-Richmond), which has a high proportion of AsianCanadians (23). The catchment of the Vancouver General Hospital also includes the downtown east side area of Vancouver, where previous studies have reported a very high prevalence of $\mathrm{HCV}$ in drug-users and sex industry workers (24). This could explain the HCV rate in our study $(4 \%)$ that is much higher than the national rate $(0.8 \%)$ as well as the high anti-HBc seropositive rate (24). We note that we did not capture ethnic demographic data, which likely represents a weakness of the present study. The absence of an association with known risk factors in our seropositive patients may also reflect the refusal of patients to disclose this information on admission to hospital, which is understandable given the social stigma and the voluntary nature of information disclosure to health care professionals. 
It is interesting that the rate of screening over time on the general medicine wards increased during this project, while the rate of screening decreased on the gastroenterology wards. Although it may be that gastroenterology truly screened less, it may also be a representation of the patients admitted to gastroenterology at the time (ie, patients with inflammatory bowel disease who had previous screening for hepatitis in anticipation of future anti-tumour necrosis factor therapy, an increase in the volume of transfers from other hospitals, etc). Given the smaller numbers of patients admitted to the gastroenterology service relative to the general medicine service, it is difficult to prove that this was, in fact, a trend.

In the greater Vancouver area, the Immunodeficiency Clinic has initiated a 'seek and treat' approach to the diagnosis of and subsequent management of HIV infection whereby all patients admitted to hospital are offered testing for HIV serology. Given the incidence of viral hepatitis in the general population and data regarding lack of screening, we suggest that our results can be used as part of an ongoing discussion regarding a 'seek and treat' approach to the detection and

\section{REFERENCES}

1. Kwong JC, Ratnasingham S, Campitelli MA, et al. The impact of infection on population health: Results of the Ontario burden of infectious diseases study. PLoS One 2012; 7:e44103.

2. BCCDC. British Columbia Annual Summary of Reportable Diseases 2009. Vancouver: BCCDC; 2010.

3. Ly KN, Xing J, Klevens M, Jiles RB, Ward JW, Holmberg SD. The increasing burden of mortality from viral hepatitis in the United States between 1999 and 2007. Ann Intern Med 2012;156:271-8.

4. Smith BD, Morgan RL, Beckett GA, et al. Recommendations for the identification of chronic hepatitis $\mathrm{C}$ infection among persons born during 1945-1965. Centers for Disease Control and Prevention MMWR 2012;61:1-31.

5. Myers RP, Ramji A, Bilodeau M, Wong S, Feld JJ. An update on the management of chronic hepatitis C: Consensus guidelines from the Canadian Association for the Study of the Liver. J Gastroenterol 2012;26:359-75.

6. Calonge N. Screening for Hepatitis C in Adults. Recommendation Statement, U.S. Preventive Services Task Force. Ann Intern Med 2004;140:462-4.

7. Moyer VA; on behalf of the U.S. Preventive Services Task Force. Screening for hepatitis $C$ virus infection in adults. U.S. Preventative Services Task Force recommendation statement. Ann Int Med 2013;159:613-9.

8. Shepherd J, Brodin H, Cave C, Waugh N, Price A, Gabbay J. Pegylated interferon alpha-2a and $-2 \mathrm{~b}$ in combination with ribavirin in the treatment of chronic hepatitis C: A systematic review and economic evaluation. Health Technol Assess 2004;8:iii-iv, 1-125.

9. Nainan OV, Alter MJ, Kruszon-Moran D, et al. Hepatits C virus genotypes and viral concentrations in paticipants of a general population survey in the United States. Gastroenterology 2006;131:478-84

10. Ward JW. The clinical epidemiology of chronic hepatitis C and one-time hepatitis $\mathrm{C}$ virus testing of persons born during 1945-1965 in the United States. Clin Liver Dis 2013;17:1-11.

11. Shepherd J, Brodin H, Cave C, Waugh N, Price A, Gabbay J. Clinical- and cost-effectiveness of pegylated interferon alpha in the treatment of chronic hepatitis C: A systemiatic review and economic evaluation. Int J Technol Assess Health Care 2005;21:47-54.

12. Coffin PO, Scott JD, Golden MR, Sullivan SD. Cost-effectiveness and population outcomes of general population screening for hepatitis C. Clin Infect Dis 2012;54:1259-71.

13. Rein DB, Smith BD, Wittenborn JS, et al. The cost-effectiveness of birth-cohort screening for hepatitis C antibody in U.S. primary care settings. Ann Intern Med 2012;156:263-70. treatment of chronic blood-borne viral illnesses. We recommend onetime screening for all patients admitted to hospital, especially those born between 1945 and 1965, and routine screening for patients with active practices exposing them to viral hepatitis transmission such as intravenous drug use, work in the sex-trade industry and after any health care worker needle-stick exposure $(4,15)$. Screening for chronic viral hepatitis in individuals with ethnic origins from endemic areas would also be advisable. Patients present to hospital with the expectation that their health will be improved, and screening for chronic viral hepatitis can be considered to be an aspect of that expectation.

ACKNOWLEDGEMENTS: The authors thank Mr Vishal Chaudhry for assistance with statistical analysis and Drs Roger Wong and Rohit Pai for their support of this project.

DISCLOSURES: The authors have no financial disclosures or conflicts of interest to declare.

14. Gustafson R, Montaner J, Sibbald B. Seek and treat to optimize HIV and AIDS prevention. CMAJ 2012;184:1971.

15. Kadatz MJ, Kapeluto J, Sidhu K, et al. Adopting the "seek and treat" model for hepatitis B and hepatitis C: The Vancouver General Hospital experience. CMAJ December 24, 2013 <www.cmaj.ca/content/184/181/1971.short/reply\#cmaj_el_713844> (Accessed June 15, 2013).

16. Smith BD, Morgan RL, Beckett GA, et al. Recommendations for the Identification of Chronic Hepatitis C Virus Infection Among Persons Born During 1945-1965. Centers for Disease Control 2012. 61(RR04);1-18.

17. Rein DB, Wittenborn JS, Weinbaum CM, et al. Forecasting the morbidity and mortality associated with prevalent cases of pre-cirrhotic chronic hepatitis C in the United States. Dig Liver Dis 2011;43:66-72.

18. Kallman JB, Arsalla A, Park V, et al. Screening for hepatitis B, C and non-alcoholic fatty liver disease: A survey of community-based physicians. Aliment Pharmacol Ther 2009;29:1019-24.

19. O'Brien SF, Xi G, Yi QL, Goldman M. Understanding nondisclosure of deferrable risk: A study of blood donors with a history of intravenous drug use. Transfus Med 2010;20:15-21.

20. Law JK, Ho JK, Hoskins PJ, et al. Fatal reactivation of hepatitis B post-chemotherapy for lymphoma in a hepatitis B surface antigennegative, hepatitis B core antibody-positive patient: Potential implications for future prophylaxis recommendations. Leuk Lymphoma 2005;46:1085-9.

21. Chen GD, Gu JL, Qiu J, Chen LZ. Outcomes of risk factors for hepatitis $\mathrm{B}$ virus (HBV) reactivation in kidney transplantation in occult hepatitis B virus carriers. Transpl Infect Dis 2013;15:300-5.

22. Wong KD, Huang FY, Lai CL, et al. Occult hepatitis B infection and hepatitis $B$ virus replicative activity in patients with cryptogenic cause of hepatocellular cancer. Hepatology 2011;54:829-36.

23. Cheung J, Lee TK, Teh CZ, et al. Cross-sectional study of hepatitis $\mathrm{B}$ awareness amongst Chinese and South-East Asian Canadians in the Vancouver Richmond community. Can J Gastroenterol 2005; 19:245-9.

24. Shannon K, Kerr T, Marshall B, et al. Survival sex with involvement as a primary risk factor for hepatitis $\mathrm{C}$ virus acquisition in drug-using youths in a Canadian setting. Arch Pediatr Adolesc Med 2010;164:61-5. 


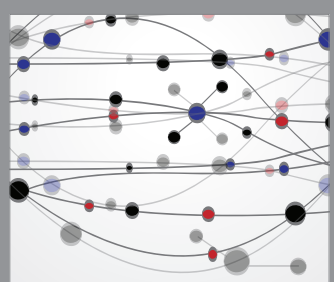

The Scientific World Journal
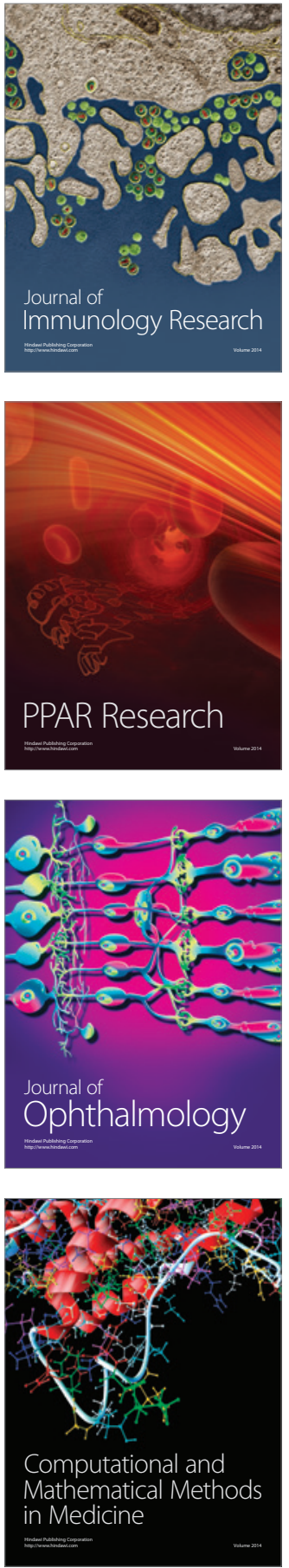

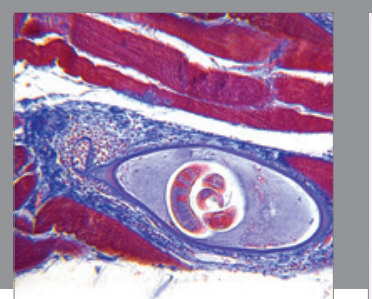

Gastroenterology Research and Practice

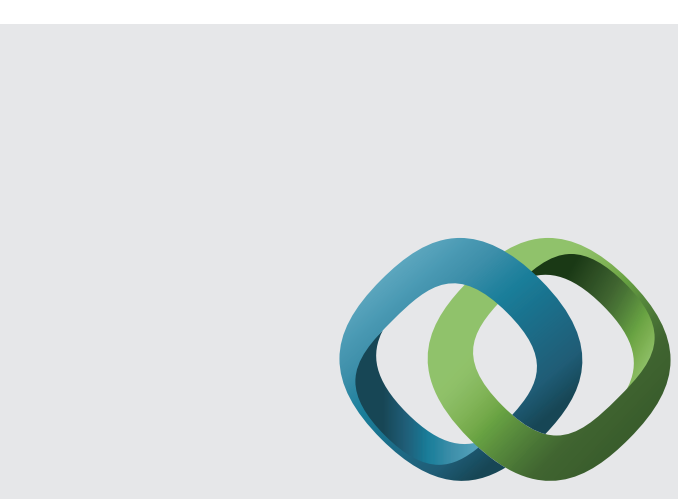

\section{Hindawi}

Submit your manuscripts at

http://www.hindawi.com
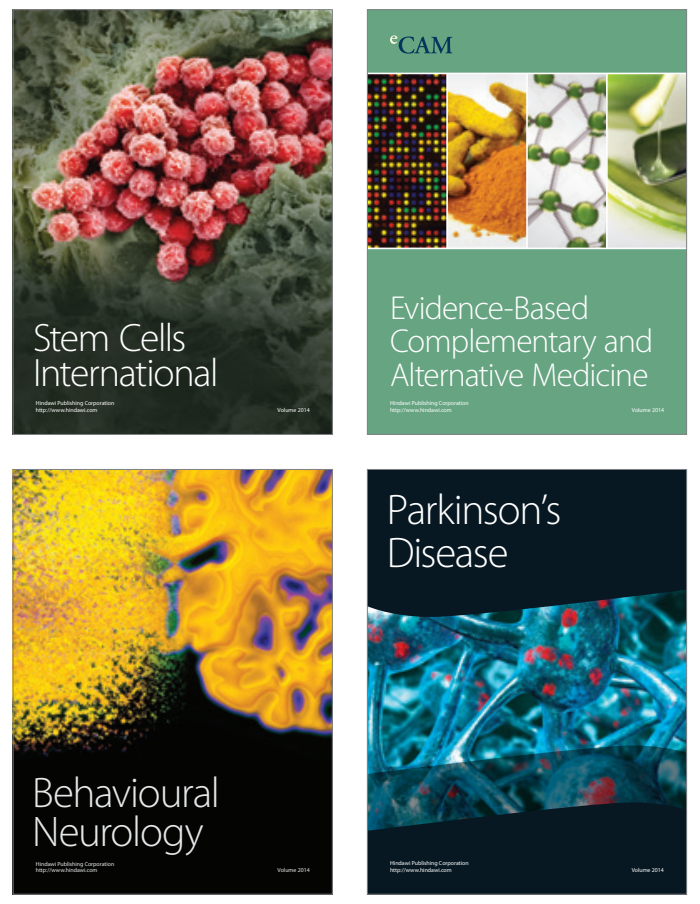
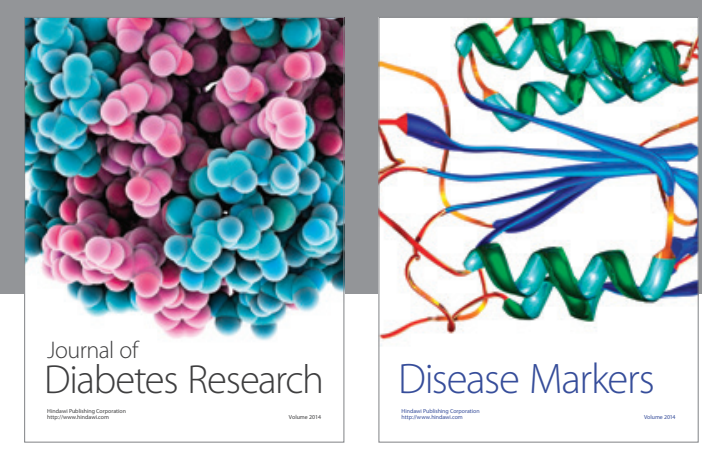

Disease Markers
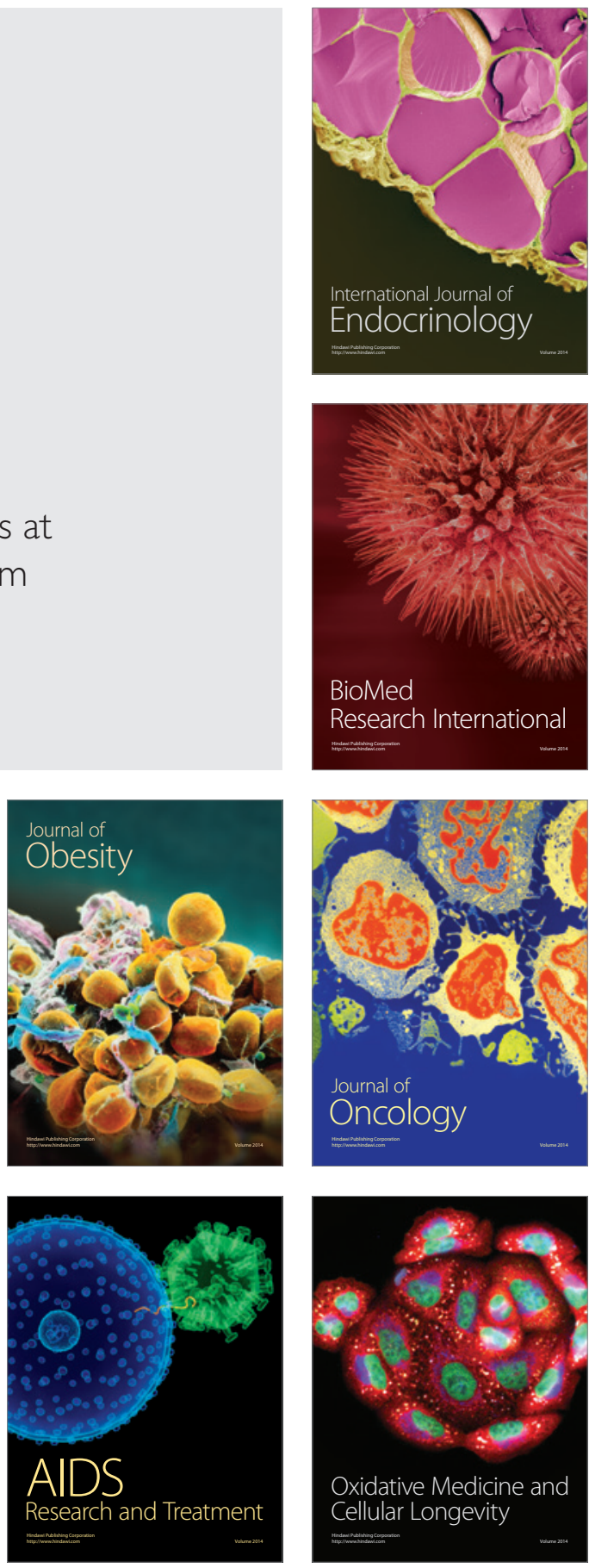